\title{
Distribution of Molecular Weight and Chemical Form of Manganese Compounds in Soybeans
}

\author{
Seisaku YoshIDA \\ Osaka Prefectural Institute of Public Health, Nakamichi, \\ Higashinari-ku, Osaka 537, Japan \\ Received February 17, 1988
}

\begin{abstract}
The chemical forms of manganese compounds in soybeans were studied. About $55 \%$ of the total manganese in soybeans was extracted into the aqueous supernatant. Separation of the aqueous supernatant by gel chromatography revealed that the ligand-binding manganese localized in three molecular weight fractions $(>100,000$, about 60,000 , and $<1,000$ ). The largest molecular weight manganese-binding compound consisted of protein, calcium, and phosphorus compoundbinding manganese. Phosphorus compound-binding manganese easily dissociated from the macromolecule by gel chromatography. Manganese in the 60,000 molecular weight fraction tightly bound to protein. This bond was affected neither by 2-mercaptoethanol, by sodium dodecyl sulfate, nor by EDTA. The lowest molecular weight ligand-binding manganese did not bind to DEAE-Sephadex A-25 resin.
\end{abstract}

Metals in foods occur in many different chemical forms. Bioavailabilities of metals in foods vary in their different chemical forms. As part of a series of studies to clarify the chemical forms of metals in foods, I have been investigating the distribution of molecular weight and the chemical form of metals in soybeans which are a very important foodstuff since they provide both protein and matals. In the course of this study, I found that the chemical forms of manganese in soybeans differed from those of copper, ${ }^{1,2)} \mathrm{zinc}^{2)}{ }^{2} \mathrm{cad}$ mium, ${ }^{3)}$ or of iron ${ }^{4)}$ which have been reported previously. Manganese is an essential element, but there is a lack of information on the distribution of molecular weight and the chemical form of manganese compounds, and its bioavailabilities in many foodstuffs. Although deficiency of manganese in human adults has not yet been reported, some disorders in infants may be related to manganese deficiency. To clarify the deficiency or the excess of manganese in infants, the distribution of molecular weights of manganese compounds have investigated in human milk, in cow's milk, and infant formulas used as substitutes for human milk. ${ }^{5)}$ Soybean is one of the major manganese sources because of its high manganese content, but there is little information on the chemical form of manganese compounds in soybeans except the isolation of acid phosphatase ${ }^{6)}$ and soybean agglutinin. ${ }^{7}$ This study documents three chemical forms of manganese compounds in the soybean aqueous supernatant.

\section{MATERIALS AND METHODS}

Plant material. The soybeans were obtained from Toyama Prefecture, Japan. The manganese content in the soybeans was $25.7 \mu \mathrm{g} / \mathrm{g}$, which was the same as the background level of ordinary soybeans. ${ }^{8)}$

Reagents. Tris(hydroxymethyl)aminomethane, 2-mercaptoethanol (2-ME), sodium dodecyl sulfate (SDS), and the standard solutions for heavy metal analysis were obtained from Wako Pure Cemical Industries. Sephadex from Pharmacia Fine Chemicals was used for gel chromatography. Standard proteins for use as molecular weight standards (bovine serum albumin, mol wt. 67,000; ovalbumin, mol wt. 45,000; chymotrypsinogen $A$, mol wt. 25,000 , and cytochrome $c$, mol wt. 12,300) were from Sigma and Pharmacia. All other chemicals were of reagent grade or a higher grade. 
Extraction. The soybeans were homogenized with a high-speed blender after being soaked overnight in ten volumes $(\mathrm{w} / \mathrm{w})$ of $0.01 \mathrm{M}$ Tris-hydrochloric acid (HCl) buffer $(\mathrm{pH} 7.4)$. The supernatant was separated from the lipid layer and the residues by ultracentrifugation at $105,000 \times g$ for $60 \mathrm{~min}$ in a Hitachi $55 \mathrm{P}-2$ centrifuge. The manganese content of the extract was $34.4 \mu \mathrm{g} / \mathrm{g}$.

Gel chromatography. The protein fraction $(\mathrm{F}-1)$ and the low-molecular weight fraction (F-II) were separated from the extract by gel filtration on Sephadex G-50 in a $2.6 \times 35 \mathrm{~cm}$ column equilibrated with $0.01 \mathrm{M}$ Tris $-\mathrm{HCl}$ buffer (pH 7.4). F-I was chromatographed on a $2 \times 75 \mathrm{~cm}$ column of Sephadex G-100 with 0.01 м Tris- $\mathrm{HCl}$ buffer (pH 7.4). The column had been previously calibrated with the molecular weight markers. The absorbance at $280 \mathrm{~nm}$ of the effluent was monitored in a flow cell.

F-II was gel filtered first on a $2.6 \times 80 \mathrm{~cm}$ column of Sephadex G-25 with $0.01 \mathrm{M}$ Tris- $\mathrm{HCl}$ buffer ( $\mathrm{pH} 7.4$ ), and the appropriate manganese-binding fraction was then rechromatographed on Sephadex G-10 in a $2 \times 80 \mathrm{~cm}$ column with $0.01 \mathrm{M}$ Tris- $\mathrm{HCl}$ buffer $(\mathrm{pH}$ 7.4). The manganese-binding component in F-Il from the gel filtration step was chromatographed on a $1.6 \times 22 \mathrm{~cm}$ DEAE-Sephadex A-25 column. The column had been equilibrated with $0.02 \mathrm{M}$ ammonium acetate buffer $(\mathrm{pH}$ 7.4), and after sample application was washed with $90 \mathrm{mI}$ of the same buffer and then eluted with a linear gradient of $0.02 \sim 0.5 \mathrm{M}$ buffer $(300 \mathrm{ml})$ at a flow rate of $30 \mathrm{ml} / \mathrm{hr}$.

Chemical treatment. F-I $(200 \mathrm{mg})$ was dissolved in $2 \mathrm{ml}$ of $0.01 \mathrm{M}$ Tris- $\mathrm{HCl}$ buffer ( $\mathrm{pH} \mathrm{7.4)}$ followed by the addition of EDTA to a final concentration of $0.01 \mathrm{M}^{2.3}$ ) After being stirred for $10 \mathrm{~min}$, the mixture was put on a $2 \times 75 \mathrm{~cm}$ Sephadex G-100 column equilibrated with $0.01 \mathrm{M}$ Tris- $\mathrm{HCl}$ buffer $(\mathrm{pH} \mathrm{7.4)}$. Another portion of F-1 (200 mg) was also dissolved in the buffer containing $2-\mathrm{ME}$ and/or SDS and chromatographed on Sephadex G-100 in the presence of 2-ME and/or SDS. The concentrations of $2-\mathrm{ME}$ and $\mathrm{SDS}$ were $0.01 \mathrm{M}$ and $0.2 \%$ in the buffer, respectively. F-1 $(160 \mathrm{mg})$ was dissolved in $2 \mathrm{ml}$ of the buffer containing $0.015 \mathrm{M}$ or $0.005 \mathrm{M}$ calcium chloride. After being stirred for $10 \mathrm{~min}$, the mixture was put on a Sephadex G-100 column and eluted with $0.01 \mathrm{M}$ Tris- $\mathrm{HCl}$ buffer ( $\mathrm{pH} 7.4)$.

Metal analysis. Manganese were measured by atomic absorption spectrophotometry with a Nippon Jarrel-Ash model AA 781. The eluate obtained on chromatography was used directly. Phosphorus was measured by the method of Bartlett ${ }^{9)}$ after ashing by a low temperature asher (International Plasma Corporation, model 1101B).

\section{RESULTS}

The manganese content of the buffer-soluble supernatant following ultracentrifugation was $34.4 \mu \mathrm{g} / \mathrm{g}$. About $55 \%$ of the total manganese in the soybeans was extracted into the supernatant.

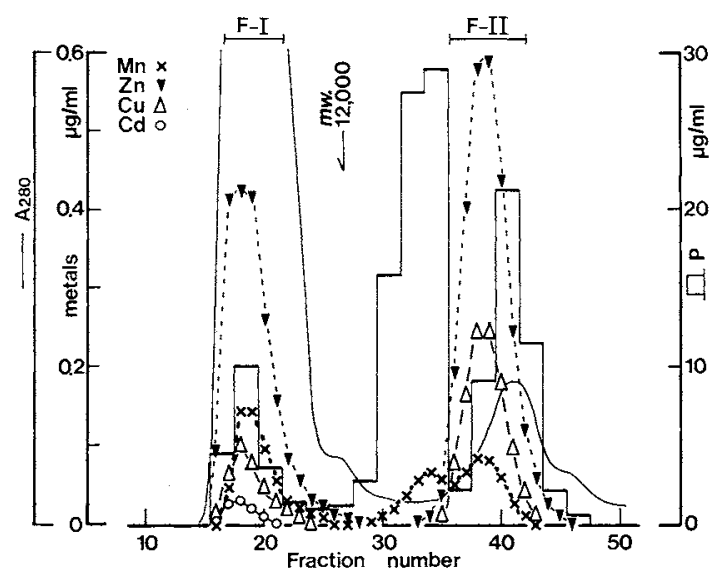

Fig. 1. Sephadex G-50 Column Chromatography of the Soybean Aqueous Supernatant.

The aqueous supernatant was put on a Sephadex G-50 column $(2.6 \times 35 \mathrm{~cm})$ and eluted at $30 \mathrm{ml} / \mathrm{hr}$ with $0.01 \mathrm{M}$ Tris- $\mathrm{HCl}$ buffer ( $\mathrm{pH} 7.4$ ). Fractions $(4 \mathrm{ml})$ were collected and analyzed for manganese, copper, zinc, cadmium, and phosphorus.

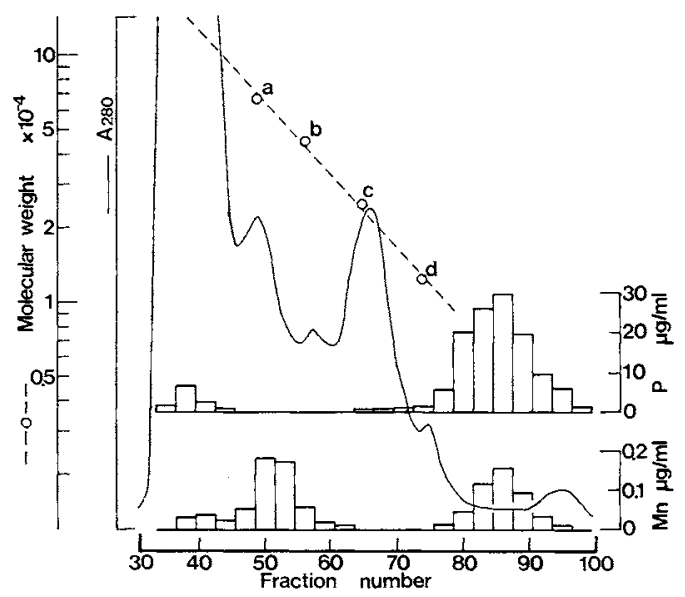

FIG. 2. Gel Filtration Chromatography of the Soybean Protein Fraction on Sephadex G-100.

F-1 encompassed in Figure 1 was pooled, desalted, and put on a Sephadex G-100 column $(2 \times 75 \mathrm{~cm})$ and eluted with $0.01 \mathrm{M}$ Tris $-\mathrm{HCl}$ buffer $(\mathrm{pH} 7.4)$. Fractions $(3 \mathrm{ml})$ were collected at a flow rate of $15 \mathrm{ml} / \mathrm{hr}$. The elution points of the standard proteins ( $m o l$ wt.): a, bovine serum albumin $(67,000)$; b, ovalbumin $(45,000)$; c, chymotrypsinogen $A(25,000)$; d, cytochrome c $(12,300)$ were plotted versus the $\log$ of the molecular weight. 

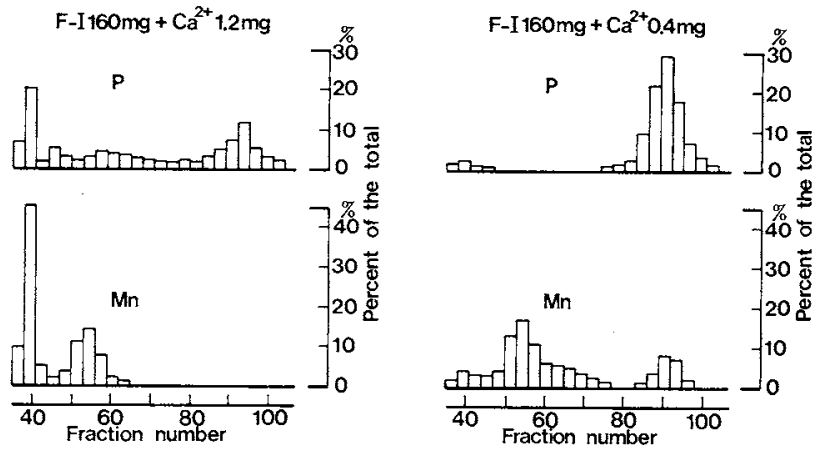

Fig. 3. Effects of Calcium on the Molecular Localization of Manganese and Phosphorus in the Soybean Protein Fraction.

F-1 ( $160 \mathrm{mg}$ ) was dissolved in the elution buffer containing $0.015 \mathrm{M}$ or $0.005 \mathrm{M}$ calcium chloride. The solution was stirred for $10 \mathrm{~min}$ and then put on the Sephadex G-100 column $(2 \times 75 \mathrm{~cm})$. The elution conditions were as described in the legend to Fig. 2.

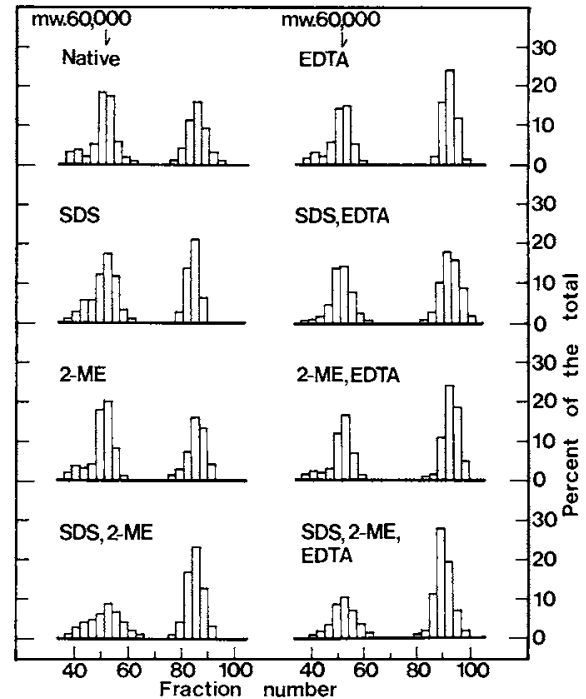

Fig. 4. Effects of EDTA, SDS and/or 2-ME on the Binding-status of Manganese in the Soybean Protein Fraction.

F-1 was dissolved in the buffer with and without SDS and/or 2-ME. EDTA was added to the sample solution to a final concentration of $0.01 \mathrm{M}$. The mixture was stirred for 10 min and put on the Sephadex G-100 column, and then eluted with the buffer in the presence and abscence of SDS and/or 2-ME. The concentrations of SDS and 2-ME in the buffer were $0.2 \%$ and $0.01 \mathrm{M}$, respectively. The other elution conditions were as described in the legend to Fig. 2.

The elution profile of manganese in the aqueous supernatant obtained from a Sephadex G-50 column are shown in Fig. 1.

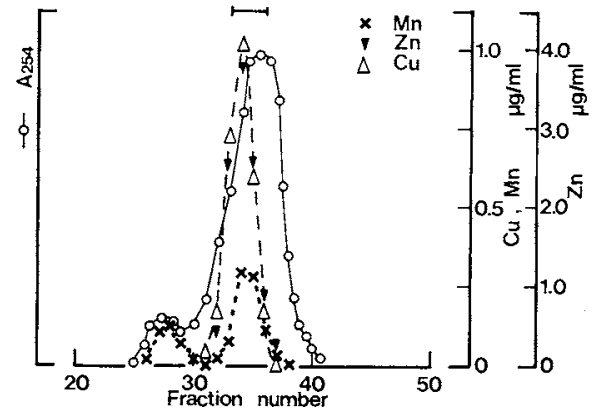

FIG. 5. Sephadex G-10 Column Chromatography of the Low Molecular Weight Ligand-binding Manganese.

The manganese-binding fraction from the Sephadex G-25 chromatography of F-11 was chromatographed on a Sephadex G-10 column $(2 \times 80 \mathrm{~cm})$ equilibrated with $0.01 \mathrm{M}$ Tris-HCl buffer $(\mathrm{pH} 7.4)$. Fractions $(3 \mathrm{ml})$ were collected at a flow rate of $20 \mathrm{ml} / \mathrm{hr}$.

Three peaks of the ligand-binding manganese were observed. The distributions of molecular weights of copper, zinc, cadmium, and phosphorus compounds are also shown in Fig. 1. The manganese-binding fraction at around the fraction number 34 contained large amounts of phosphorus compounds. When F-1 was stored for a few days and rechromatographed on the Sephadex G-50, the large proportion of manganese in F-1 was found to move to the lower molecular weight fraction, at the fraction number 34 in Fig. 1, with the phosphorus compounds.

F-1 was chromatographed on a Sephadex 


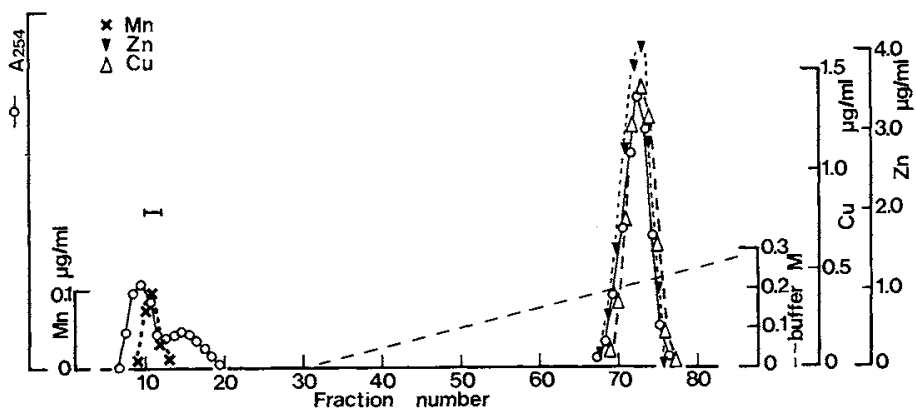

FIG. 6. DEAE-Sephadex A-25 Column Chromatography of the Low Molecular Weight Ligand-binding Manganese.

The column $(1.6 \times 22 \mathrm{~cm})$ was equilibrated with $0.02 \mathrm{M}$ ammonium acetate buffer $(\mathrm{pH} 7.4)$. After sample application, the column was washed with $90 \mathrm{ml}$ of the buffer and then the sample was eluted with a linear gradient of $0.2 \sim 0.5 \mathrm{M}$ buffer $(300 \mathrm{ml})$. Fractions $(3 \mathrm{ml})$ were collected at a flow rate of $30 \mathrm{ml} / \mathrm{hr}$.

G-100 column (Fig. 2). Three ligand-binding manganese were found in the molecular weight fraction of $>100,000$, about 60,000 , and $<10,000$. Small amounts of phosphorus were found at the macromolecule of $>100,000$ in mol wt. Large amounts of phosphorus with manganese in F-1 was observed to be released from the macromolecules by gel chromatography. For the identification of the original ligand of the released manganese in F-1, the reconstitution of the original manganese complex in F-l was tried. Figure 3 shows the elution profile of manganese in F-1 after the addition of calcium ion to F-1 in two concentrations. When sufficient calcium ion was given, all of the manganese was released and about half the amount of phosphorus in lower molecules were shifted again to the macro-. molecule of $>100,000$ in mol wt. Calcium ion functioned as a joining material between proteins of $>100,000$ in mol wt. and phosphorus compound-bound manganese. The 60,000 molecular weight manganese compound has no phosphorus, and no effect was observed on its binding status by treatment with calcium ion.

The effects of EDTA, SDS and/or 2-ME on the binding status of the ligand-binding manganese in F-1 were studied (Fig. 4). Upon addition of EDTA to F-1, manganese that was associated with the phosphorus compounds, both at the fraction of $>100,000$ in mol wt. and at the fraction of $<10,000 \mathrm{in} \mathrm{mol}$ wt., were taken away from the ligand by the chelating action of EDTA. On the other hand, no effect was observed on the binding status between manganese and the 60,000 molecular weight protein by treatment with EDTA. No change was also observed on the distribution of molecular weight 60,000 protein-binding manganese by treatment with SDS and/or 2ME.

A Sephadex G-10 gel chromatogram of the ligand-binding manganese in F-II following the Sephadex G-25 chromatography is shown in Fig. 5. Two peaks of ligand-binding manganese were found. Manganese at the void volume was the phosphorus compoundbinding manganese. The lowest molecular weight ligand-binding manganese always eluted with copper and zinc complexes on the gel filtration chromatography. When this metalbinding fraction was chromatographed on a DEAE-Sephadex A-25 column, manganese compounds could separate from copper and zinc compounds, because manganese compounds did not bind to the DEAE-Sephadex A-25 resin (Fig. 6).

\section{DISCUSSION}

About $55 \%$ of the total manganese in the soybeans were extracted into the supernatant. One third of the manganese in the supernatant was associated primarily in the fraction of 
$>100,000$ in mol wt., one third was in the 60,000 molecular weight fraction, and the residual one third complexed to the ligand with mol wt. less than 1,000 .

The macromolecule manganese complex of $>100,000$ in mol wt. was proved to consist of protein, calcium, and phosphorus compoundbinding manganese. Calcium ion was the intermediate between protein and phosphorus compound-binding manganese. Saio et al. ${ }^{10}$ reported earlier that soybean meal protein binds phytic acid in combination with calcium. In their report, other minerals were not mentioned. By the addition of calcium ion, soybean globulins bind manganese with phytate in company with calcium ion.

Phosphorus and calcium were known to reduce mineral absorption by binding and making insoluble complexes in the intestine. In this study, the significant participation of phosphorus and calcium on the chemicl form of manganese was observed. One third of the manganese in the soybean aqueous supernatant bound to the phosphorus compound. If phosphorus compounds are removed before the use of soybean meal protein, one third of the manganese in the soybean aqueous supernatant will be removed at the same time. Manganese bound to phosphorus compound in the soybean supernatant was found to be easily removed by EDTA. This suggests that the chelating agents supplementation may enhance the manganese absorption from the soybean supernatant. ${ }^{11)}$

Molecular weight 60,000 manganese binding protein has not yet reported from soybeans. Manganoproteins isolated from soybeans were soybean agglutinin (mol wt. 120,000) ${ }^{7)}$ and acid phosphatase (mol wt. 240,000). ${ }^{6)}$ All of the molecular weights of other manganoproteins isolated from plants, such as; superoxide dismutase, ${ }^{12)}$ concanavalin A from jack bean, ${ }^{13)}$ and manganin from peanut seeds, ${ }^{14)}$ are not 60,000 . Among them, the molecular weight of manganin from peanut seeds, 57,000, is the closest to the molecular weight 60,000 of the manganoprotein in soybean seeds. The bond between manganese and this 60,000 molecular weight protein was very stable. Neither EDTA, SDS, nor 2-ME could affect the binding status of this manganoprotein. This manganoprotein may have some vital function. Further purification of this manganoprotein is under way now.

Though low molecular weight ligandbinding manganese always eluted with copper and zinc on Sephadex G-25 and G-10 chromatography, it did not bind to the DEAE resin, distinct from the behavior of the low molecular weight ligand-binding copper and zinc. Manganese complex in F-II may have the different chemical form from that of copper and zinc. There was little phosphorus in the lowest molecular weight manganese fraction. The bioavailability of this low molecular weight manganese complex needs to be assessed.

\section{REFERENCES}

1) S. Yoshida, R. Tanaka and T. Kashimoto, J. Food Hyg. Soc. Jpn., 23, 53 (1982).

2) S. Yoshida, R. Tanaka and T. Kashimoto, J. Food Hyg. Soc. Jpn., 24, 550 (1983); S. Yoshida, R. Tanaka and T. Kashimoto, J. Food Hyg. Soc. Jpn., 27, 70 (1986).

3) S. Yoshida, R. Tanaka and T. Kashimoto, J. Food Hyg. Soc. Jpn., 27, 64 (1986); S. Yoshida, Agric. Biol. Chem., 50, 2273 (1986)

4) S. Yoshida, Proc. Osaka Pref. Inst. Publ. Health, 18, 29 (1987).

5) W.-Y. Chan, J. M. Bates, Jr. and O. M. Rennert, $J$. Nutr., 112, 642 (1982); B. Lonnerdal, C. L. Keen and L. S. Hurley, Am. J. Clin. Nutr., 41, 550 (1985).

6) S. Fujimoto, T. Nakagawa and A. Ohara, Agric. Biol. Chem., 41, 599 (1977).

7) R. Lotan, H. W. Siegelman, H. Lis and N. Sharon, $J$. Biol. Chem., 249, 1219 (1974).

8) R. Tanaka, K. Ikebe, Y. Tanaka and N. Kunita, $J$. Food Hyg. Soc. Jpn., 24, 488 (1983).

9) G. R. Bartlett, J. Biol. Chem., 234, 466 (1959).

10) K. Saio, E. Koyama and T. Watanabe, Agric. Biol. Chem., 32, 448 (1968).

11) P. N. Davis, L. C. Norris and F. H. Kratzer, J. Nutr., 77, 217 (1961).

12) I. Fridovich, Adv. Enzymol., 41, 35 (1974).

13) B. B. L. Agrawal and I. J. Goldstein, Biochim. Biophys. Acta, 147, 262 (1967).

14) J. W. Dieckert and E. Rozacky, Arch. Biochem. Biophys, 134, 473 (1969). 